\title{
Recrystallization: the Actual Topics with Particular Focus on the Investigation of Transformation Kinetics
}

\author{
F. Haessner \\ Technische Universität Braunschweig, Germany \\ Institut für Werkstoffe
}

\begin{abstract}
An attempt will be made to give an overview of the main areas of actual interest with respect to recent progress and to future prospects in the respective fields. In this connection the following areas are treated: The kind of material and the initial thermodynamical unstable state; the basic processes during heating up of a sample: recovery, nucleation, grain boundary migration; the end product, which is the result of an interaction of the basic processes. From these different areas attention is turned to the topic of "kinetics", focussing particularly on what we can learn about recrystallization- and recovery-kinetics in metals as a result of modern calorimetric investigation.
\end{abstract}

\section{INTRODUCTION}

When the organisers of the colloquium asked me whether I would be willing to give a survey lecture on the actual state of the art of recrystallization problems, I was honoured by the trust placed in me and, after some thought, rather bewildered, because the desired topic represents a complex conglomerate of interwoven information, accepted views and controversial opinions. One way to unravel the mystery and give it structure is to look out for topical subjects. That is how the title of my talk originated.

The paper is organized in the following way: To begin with an overview is given on the main areas of relevant interest with respect to recent progress and to future prospects in the respective fields. From these different areas the topic "kinetics" is treated in more detail, particularly the point: what can we learn about recrystallization and recovery kinetics in metals as a result of modern calorimetric investigation? This field has been chosen for three reasons: We are dealing with a central area of recrystallization; the field reflects rather well the ambivalence of agreement and scepticism so characteristic of many aspects of recrystallization; finally, the author can speak from experience.

The search for topical subjects is not difficult, perhaps a little tedious. One has to look through the literature and the pertinent conference proceedings $/ 1-8 /$. It is a great deal more difficult however, to testify where notable progress has been made in recent times. Yet more delicate is the assessment of future potential. The reasons for this are manifold. Among other things, the valuation of a field depends on whether:

(i) primarily scientific or practical criteria are involved (A typical example in this respect are grain growth phenomena in thin films. These processes are of great importance in the computer industry),

(ii) young highflyers or old sceptics are offering their verdict (typical here is the valution of computer simulation and modelling). 
In order to obtain an objective valuation of the topical subjects from a scientific viewpoint, the author asked about 30 experts worldwide for their opinions. Therefore, what will be said about the topics in the first section is the author's personal view, influenced by many colleagues.

To keep to the thread throughout, one can attempt to accommodate the whole recrystallization field in a systematic scheme. This is more or less inevitable, considering the life of a sample from its beginning to its final state. First of all we need information about the starting point: The sort of material we are dealing with and the initial thermodynamical unstable state. After that, the sample will be heated up. In a simplified sense, three basic processes can occur in the material: recovery, nucleation, grain boundary migration. Finally, we have to consider the end product which is the result of an interaction of these basic processes. After this curriculum vitae of a sample, we will take a look at those areas which have attracted the most attention in recent years and how the activity should be assessed.

\section{THE ACTUAL TOPICS}

\section{Type of Material}

Most activities have been devoted to metallic materials either single- or multiphase in constitution. But within this group there are some fields which have been studied rather less, despite their practical relevance: ordered alloys, intermetallics, composites or multiphase systems, in which interaction of recrystallization with other reactions can occur [see for instance /9-11, 47/]. The same holds for nonmetallic materials such as ceramics.

\section{Thermodynamical Unstable State}

An accurate microstructural desciption of the initial state is, from a fundamental point of view, an essential prerequisite for understanding the processes which take place in recrystallization. This also holds for practical applications. The whole complex may be regarded from two standpoints: The generation of instability and the characterization of the unstable state. Both areas have excited much interest, in the first instance the points listed in Fig. $\left.1 .^{1}\right)$ Remarkable progress, recorded by square dots ( $\bullet$ ), has been made in all of these fields besides in "grain morphology" and "arrangement of lattice defects". The future potential is probably particularly high in the areas characterized by an exclamation mark (!). This valuation of future potential is based on the availability of new or improved experimental techniques. Local values for instance can be determined nowadays rather precisely and fast in the electron microscope by nanobeam technique and by automated image processing $16,12 \%$. In the field of thermodynamic quantities powerful calorimeric devices are available [see for instance /13,14/]. A selection of recent contributions which are relevant to the matter handled in this subdivision is collated in Fig. 1 (and Figs 2-4) behind the respective topics.

\section{Recovery and Nucleation}

The joint treatment of recovery and nucleation is a consequence of the fact that, upon annealing, these two processes are generally the first to take their course in a plastically deformed metal. Theoretically, recovery and nucleation may be clearly differentiated in a well-defined way. In practice, this can prove difficult since both processes may overlap more or less strongly, according to the material. As a result, controversial opinions abound in this area. In addition there is a basic difficulty inherent in the term "nucleation": measurements register "perceptible nucleation", which may be related to a larger or smaller extent to growth processes.

1) There exist, of course, many more possibilities to produce instability than recorded in Fig. 1, for instance by quenching, particle bombardment, thermomechanical treatment etc. of a sample. The same holds for the subdivision of characterization, for instance by quantities like texture, strain gradient, magnetization, degree of order etc. These items which have not attracted too much attention in recent years have been indicated in Fig. 1 by dotted lines resp. by X.Y.

The same selection criterion holds for the following Figs. 2-4. 


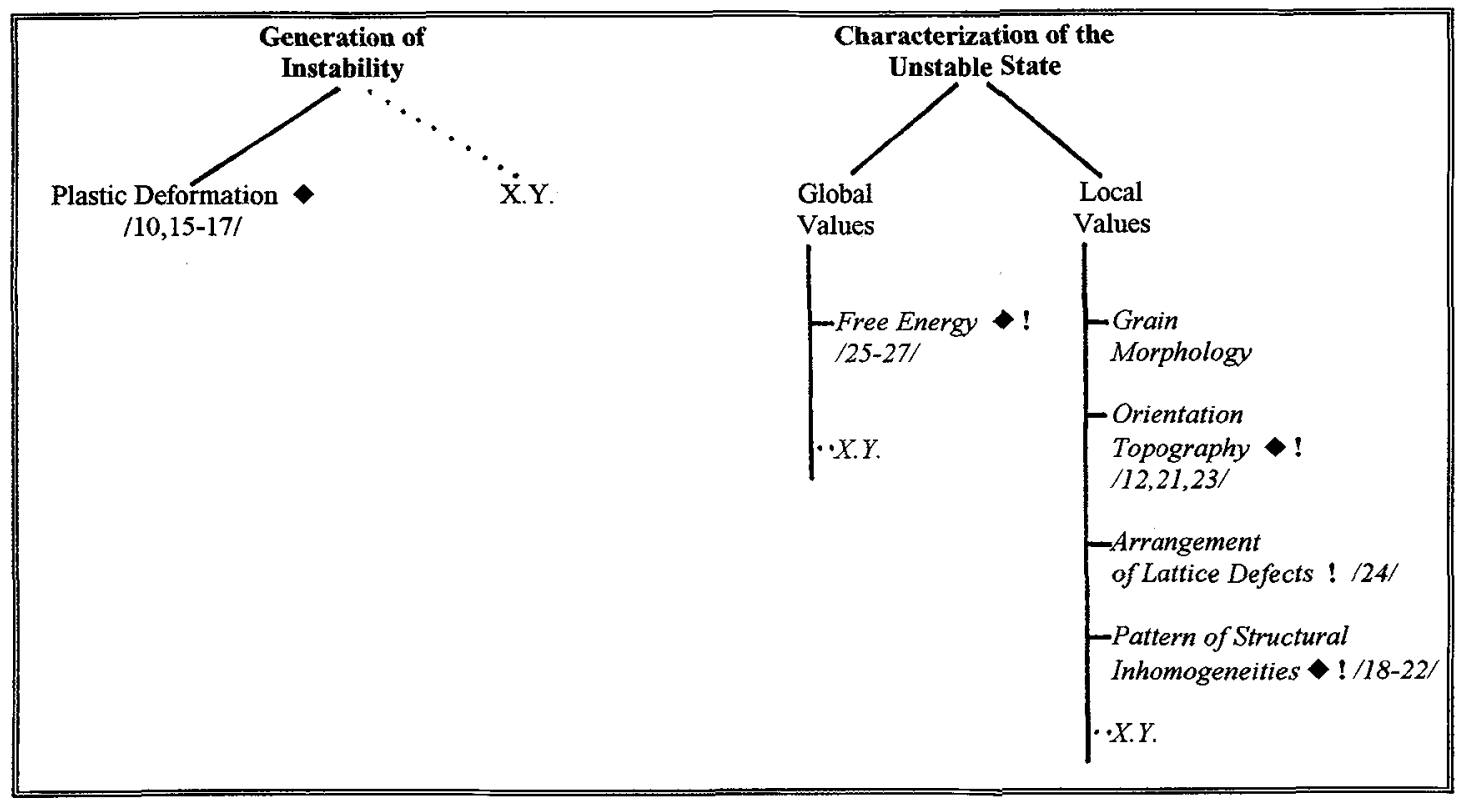

Fig. 1: Initial unstable state

The complex can be headed: energetic versus structural aspects, structural and chemical features, mechanisms and models. Compared with the last, the first two areas have received much attention: namely the points mentioned in Fig. 2 in particular. In all these areas remarkable progress $(\bullet)$ is evident. The future potential (!), too, may be judged noteworthy. This assessment of future development is based as before on new and improved measuring probes and preparatory techniques. Consequently, considerable enhancement of our knowledge in the future is anticipated.
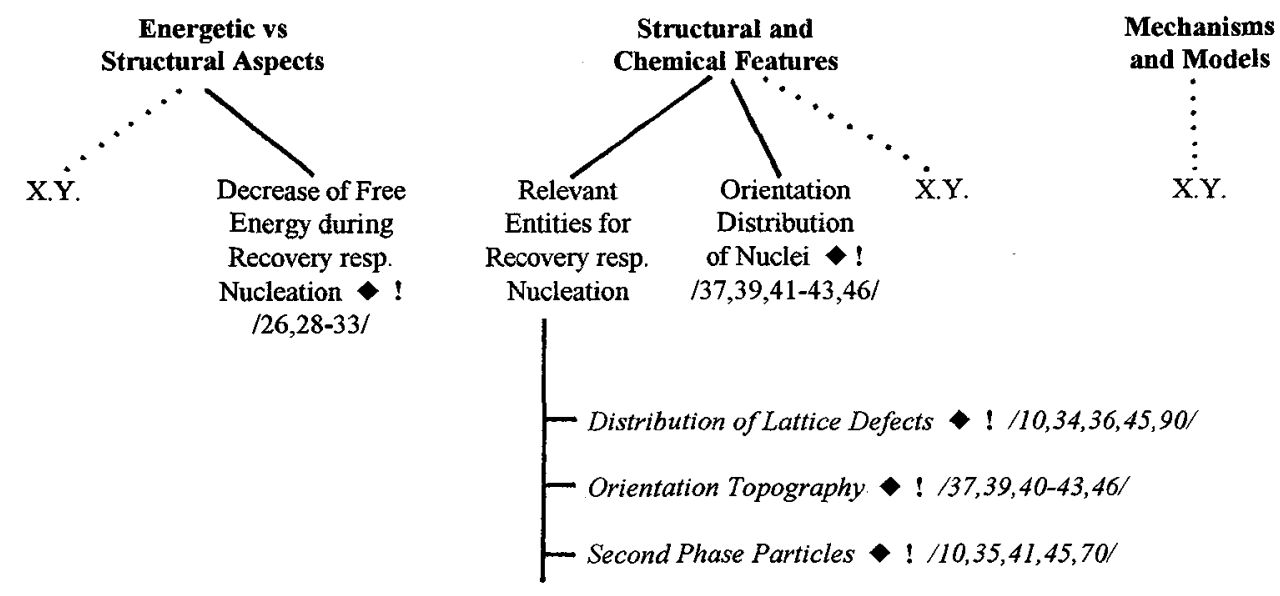

Fig. 2: Recovery and Nucleation 


\section{Grain Boundary Migration}

After the formation of nuclei, i.e. large-angle grain boundaries, the next process during annealing is the migration of grain boundaries. It is appropriate to divide this complex further into the characterisation of static grain boundaries and features of moving grain boundaries. Both areas have received much attention. In particular the questions listed in Fig. 3. Remarkable progress $(\bullet)$ has been made in all of these fields. For three of these the future potential (!) is estimated to be high. The reasons are, as before, new and better techniques [see for instance $/ 68,69 /$ ]. For the points "atomistic and electronic features" and "simulation models", it is the use of powerful computers. The number of recent contributions to this subdivision is substantially larger than that to the subdivision considered above. One reason for that may be due to the fact that the experimental approach of following grain boundary migration is easier than to "see" recovery or nucleation.

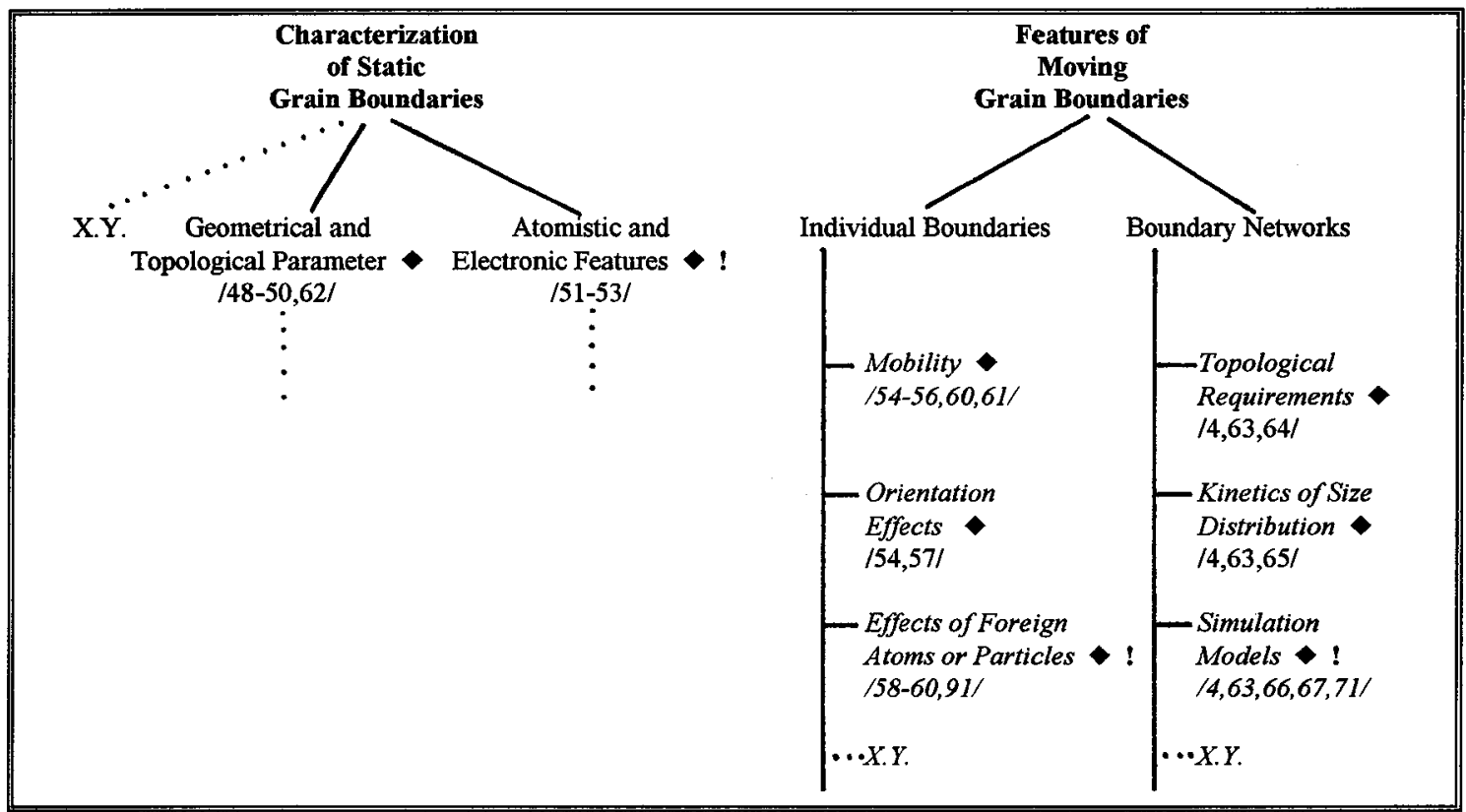

Fig. 3: Grain boundary migration

\section{Examples of Integral Results}

Out of the profusion of examples three particularly important complexes may be presented: kinetics of transformation and microstructural evolution, recrystallization textures, recovery and recrystallization during deformation. The following subdivisions have received rather a lot of attention (Fig. 4). In all of these areas, remarkable progress $(\diamond)$ has been achieved. The future potential (!) of about half of these areas is estimated to be high. This assessment is based on a scientific viewpoint. With respect to the practical relevance the assessment may be quite different, as is shown by the following three examples:

(i) Microstructural Evolution

The understanding of the evolution towards a specific structure, for instance the bamboo structure, is very important in the context of thin films, which are used as interconnecting lines in integrated circuits. The microstructure of such films has a direct effect on their reliability and resistance to electromigration failure. 


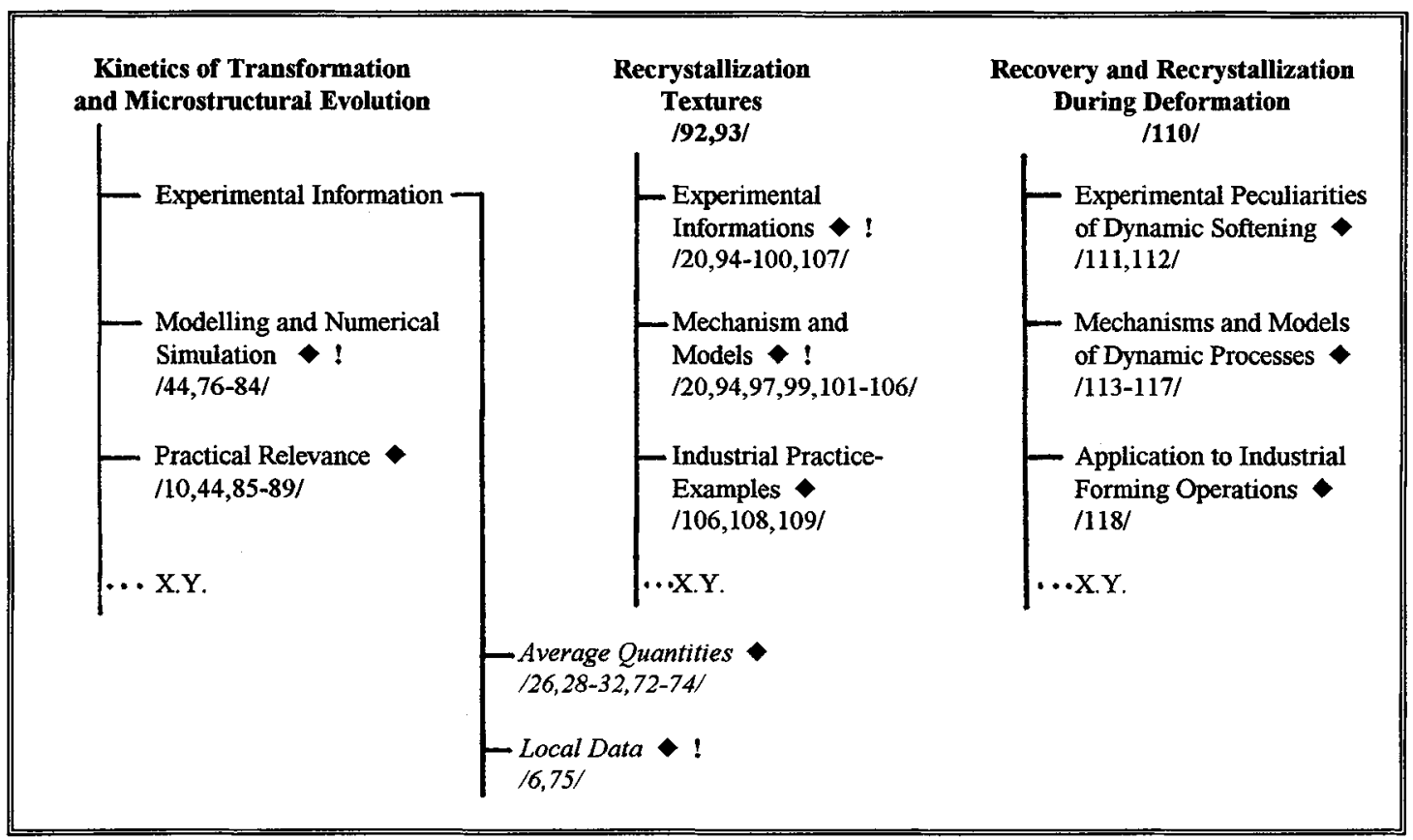

Fig. 4: Examples of integral results.

(ii) Recrystallization Textures

The performance of grain-oriented silicon steel depends on the sharpness and fraction of the (110) [001], (100) [001] and (100) [011] texture components. One critical point in the production line is to control the frequency of $\Sigma 7$ and $\Sigma 9$ coincidence orientation relationships between the matrix grain orientations before grain growth, that is, in the primary recrystallization stage, and selected nuclei.

(iii) Recrystallization Textures and Dynamic Recrystallization

The manufacture of Al-sheet for Can Bodystock is that of balancing cold rolling textures with those that are produced during hot rolling in order to reduce microstructural anisotropy, especially earing. The critical point is the distribution of second phase particles.

\section{Résumé}

Upon reviewing the first part, and regarding it with historical hindsight, perhaps over-subtly, one can summarize as follows: The field of recrystallization has for a number of years until the present day made progress in an evolutionary rather than in a revolutionary mode: The investigators of the subject seem only to consolidate and build slowly upon foundations that were laid some years ago. In a few cases erroneous concepts were corrected. With the introduction of the computer we have become a little more sophisticated in our models, in the procuring and processing of data, and so on. Hence, if signs of revolutionary progress can be confirmed somewhere, they are based on the novel and improved experimental procedures, rather than primarily on new ideas or concepts.

\section{WHAT CAN WE LEARN ABOUT TRANSFORMATION KINETICS FROM MODERN CALORIMETRIC INVESTIGATION?}

The research on and description of recovery and recrystallization kinetics, that is, the statement of a transformed fraction as a function of temperature and time, is of major scientific interest and important in 
a wide range of industrial applications. In thermo-mechanical processing, for instance, reliable prediction of the transformation kinetics is needed in order to optimize the processing conditions and the finished product.

A particularly promising and in recent times frequently employed method of determining transformation kinetics is the calorimetric measurement of the heat liberated during the process of recovery or recrystallization $125 \%$. This method comes very close to the fundamentals of transformation thermodynamics, namely the minimisation of free enthalpy. Modern calorimeters measure the thermal power, i.e. the energy released by a sample in unit time, which is a measure of the momentary rate of the process taking place in the sample $/ 13,14$. This peculiarity distinguishes calorimetry from other methods of kinetic study. The instantaneous calorimetric signal is well-resolved under favourable boundary conditions and itself shows high accuracy. The accuracy of the measurement is further increased by the integration during evaluation. Finally, in modern calorimeters, without changing the experimental setup, it is possible to perform measurements at constant temperature or at a constant rate of heating, so that a comparison or coupling of both methods can yield new information.

On the other hand, calorimetric measurements alone do not allow conclusions to be drawn about the state of the material during a transformation. Occasionally it has been disputed whether calorimetric data is actually capable of describing the recrystallized fraction correctly. Auxiliary measurements or models are necessary for that. This disadvantage is probably the main reason for a certain degree of scepticism concerning the usefulness of calorimetric measurements for a better understanding of recovery and recrystallization processes, despite the aforementioned advantages. This assessment is unjustified as will be illustrated in the following with an exemplary demonstration of recent results concerning the most exact statement of the transformation kinetics during the annealing of cold-rolled copper $/ 33 /$. A series of calorimetric data were available which had been determined for $92 \%$ rolled copper in a modern heat flow calorimeter for both isothermal and non-isothermal experimental runs.

Figs. $5 \mathrm{a}, \mathrm{b}$ show a selection of the measured heat flow curves. The isothermal measurements show another exothermal reaction before the primary recrystallization, exponentially decreasing in character, which can account for up to about $10 \%$ of the total stored energy to be released. This reaction can be attributed to dislocation recovery. In non-isothermal measurements this reaction manifests itself by a ramp preceding the main peak. Since the measured heat flow is proportional to the rate of reaction, suitable integration of the data yields the transformed fraction. The equivalence of the calorimetrically determined transformed fraction with the stereologically measured recrystallized fraction (by the electron back scattering pattern technique) is shown in Fig. $6 / 119 /$. The calorimetric data are well within the experimental scatter of the EBSP data.

(a)

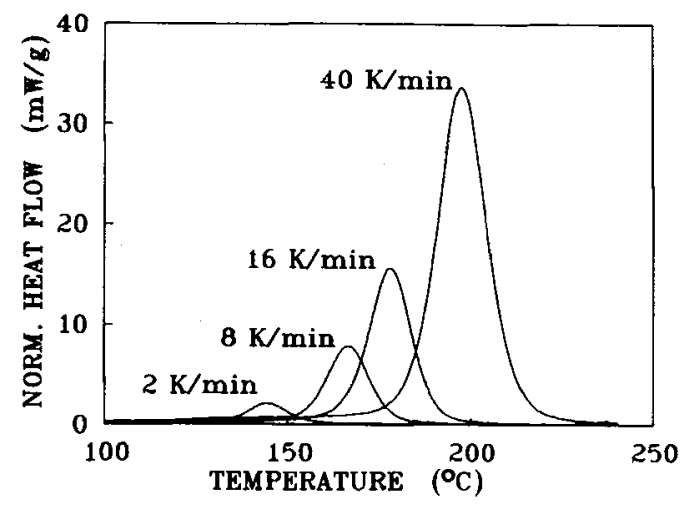

(b)

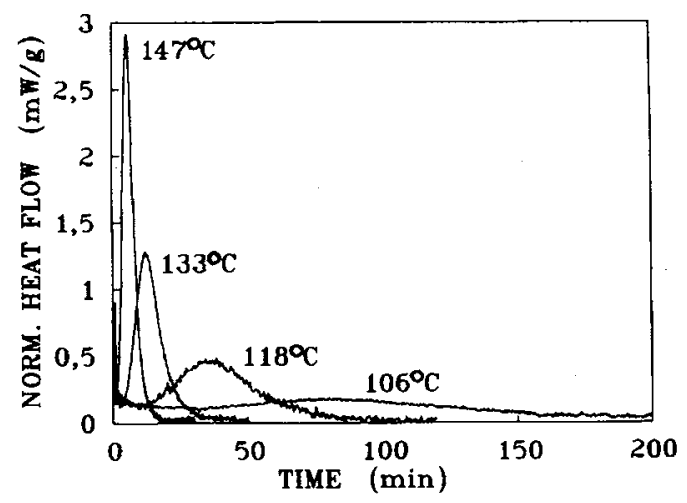

Fig. 5: (a) Isothermal DSC results for temperatures of $106,118,133$ and $147^{\circ} \mathrm{C}$, (b) non-isothermal DSC results for constant heating rates of $2,8,16$ and $40 \mathrm{~K} / \mathrm{min} / 33 /$. 


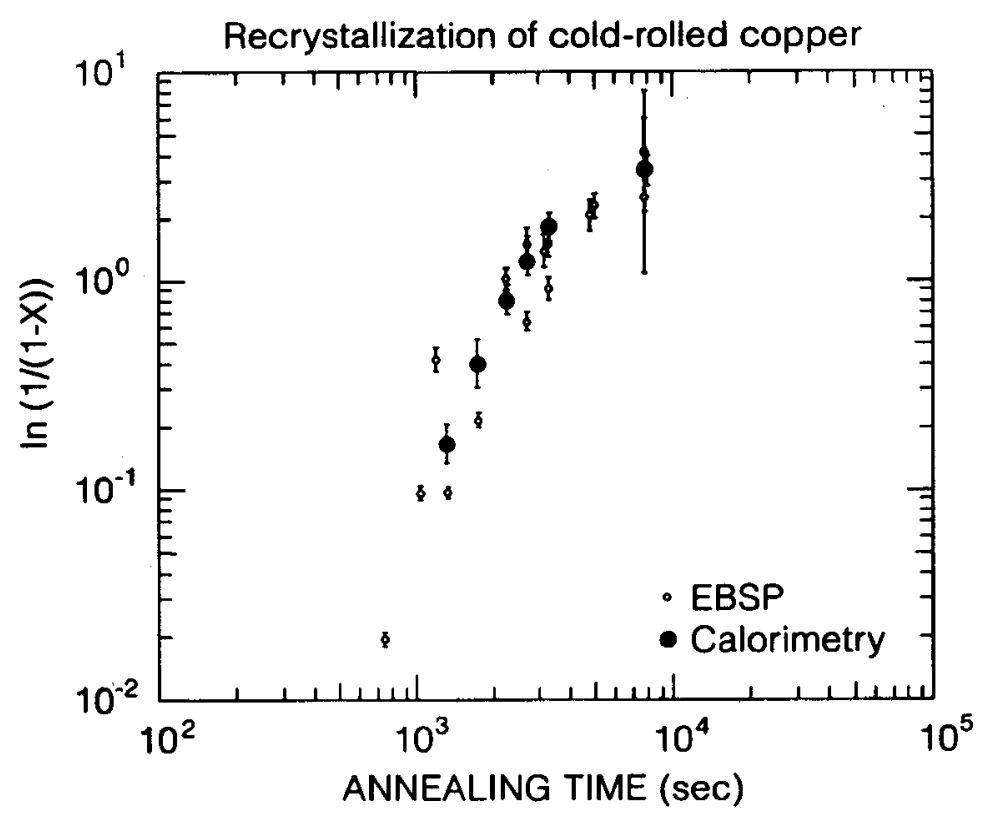

Fig.6: Equivalence of the transformed fraction determined by calorimetry and stereologically (EBSP: Electron Back Scattering Pattern Technique) /119/.

If, as is usually the case, it is assumed that primary recrystallization takes place according to the JohnsonMehl-Avrami-Kolmogorov ("JMAK") formalism /120/, a comprehensive kinetic analysis of the calorimetric data can be carried out $/ 33$. Analyses of this kind may of course also be performed using other measured data. The accuracy of the data is the decisive factor; and this is particularly good for calorimetric data. The objective of a kinetic analysis is the determination of the transformation parameters of the transformation function, the activation parameter and the Avrami exponent. For the isothermal measurements the necessary equipment is established standard technique. For the non-isothermal measurements the correct implementation has only become available in the last two years $/ 121$.

In Fig. 7 the time dependence of the recrystallized fraction $X_{i}(t)$, determined from the isothermal measurements, purged of the recovery portion, is shown in a double logarithmic plot for the example of an annealing temperature of $112^{\circ} \mathrm{C}$. If the reaction were to progress according to the JMAK kinetics, then a straight line with the Avrami exponent as slope should result. Similar curves are obtained for the other temperatures studied. If the slope is determined from the fitted straight lines the Avrami exponent shows a linear increase with temperature. For the initial stage of the reaction $\left(\mathrm{X}_{\mathrm{i}} \leq 20 \%\right)$ the activation energy takes a value of $Q^{i}=78,2 \mathrm{~kJ} / \mathrm{mol}$.

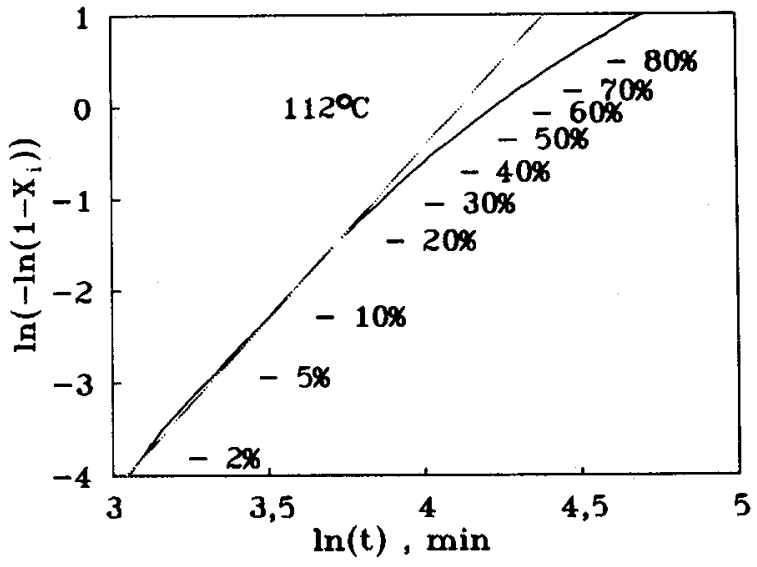

Fig. 7: Doublelog-plot for the isothermal DSC measurement at $112^{\circ} \mathrm{C}$ after subtraction of the recovery component $/ 33 /$. 
With the aid of the correct evaluation equipment $/ 121 /$, (extension of the wellknown Kissinger analysis), the nonisothermal measurements yield an activation energy of $\mathrm{Q}^{\mathrm{a}}=85,5 \mathrm{~kJ} / \mathrm{mol}$ $\left(X_{a} \geq 20 \%\right)$. With that, the nonisothermally determined transformed fraction $X_{a}$ can be plotted double logarithmically in modified form. Fig. 8 shows the result for a heating rate of 8 $\mathrm{K} / \mathrm{min}$. Instead of the ideally expected straight line, an S-shaped curve is obtained. which can only be described as straight in its centre part. Similar curves are also obtained for the other heating rates.

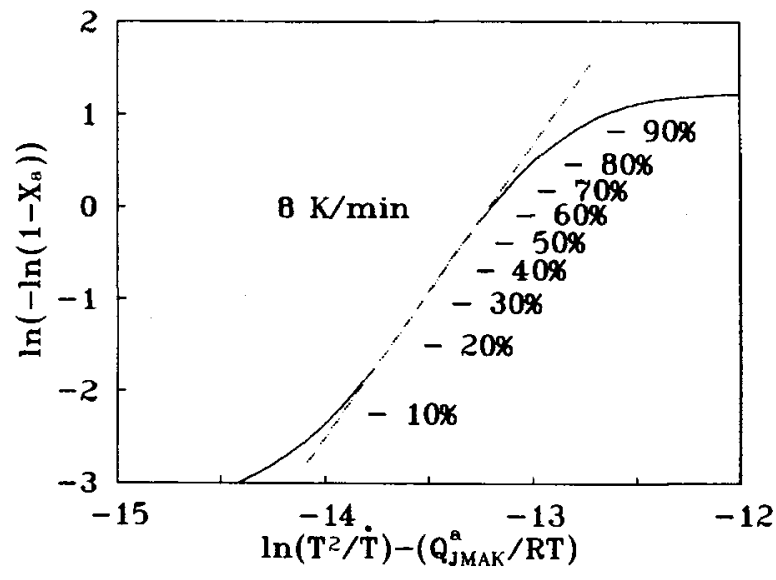

Fig. 8: Modified doublelog-plot to extract the non-isothermal Avrami exponent from a DSC measurement with a constant heating rate of $8 \mathrm{~K} / \mathrm{min} / 33 /$.

Thus the analysis of the isothermal and non-isothermal measurements shows clear divergence from the predictions of the JMAK theory:

$\rightarrow \quad$ no straight plots in double logarithmic axes

$\rightarrow \quad$ the isothermal Avrami exponent is temperature dependent

$\rightarrow \quad$ the isothermal and non-isothermal activation energies differ considerably.

Similar discrepancies in the recrystallization of copper and other metals have previously been observed and described $/ 122,123 /$. The causes were generally assumed to be insufficient accuracy, simultaneously occurring recovery or an inhomogeneous deformation state /124/. Insufficient accuracy of measurement is not a problem for the topical calorimetric data presented here. Recovery, too, cannot be used in explanation. Presumably the causes lie in the material itself. They make a simple description using the standard JMAK theory impossible.

The fundamental prerequisite for the JMAK theory is spatially homogeneous material. This assumption leads to a single fixed activation energy for the whole process. If one drops the condition of global homogeneity, and works instead with the assumption that the material can be divided into locally independent areas, then these areas can be assigned different nucleation and growth conditions with the appropriate standard JMAK kinetics $/ 125 /$. The total transformation of a sample is then the overlap of the JMAK processes of the individual areas with their different activation energies.

If this kind of extension of JMAK kinetics is consistently applied to the calorimetric data described /33/, i.e. an activation energy distribution ("AED") is used instead of a single activation energy, there is excellent agreement between measured transformation kinetics and predicted kinetics. This is demonstrated by the examples in Figs. 9a, b: the first plot shows a comparison of the measured isothermal transformation curve at $\mathrm{T}=130^{\circ} \mathrm{C}$ (represented by the symbols) with its description based on the AED-fit and the individual standard JMAK-fit. The second, even more striking plot, shows a comparison of a measured isothermal transformation curve $\mathrm{T}=139^{\circ} \mathrm{C}$ (symbols), with a calculated transformation curve based on AED derived from non-isothermal measurement with a heating rate of $\dot{T}=16 \mathrm{~K} / \mathrm{min}$ (solid line). The discrepancy at the beginning of the curves is mainly due to incorrect consideration of the dislocation recovery. 
(a)

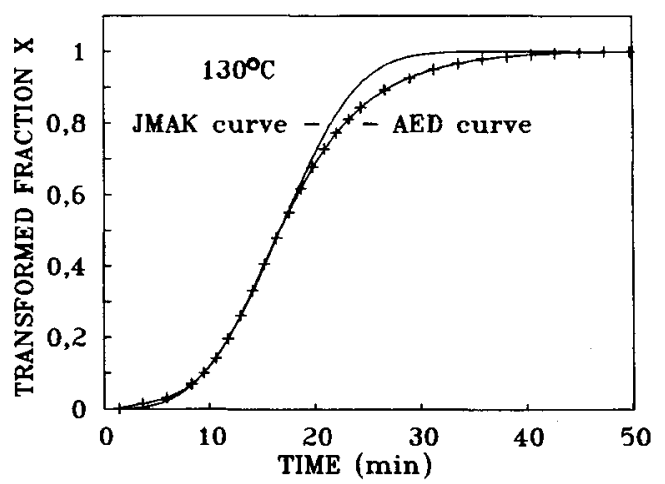

(b)

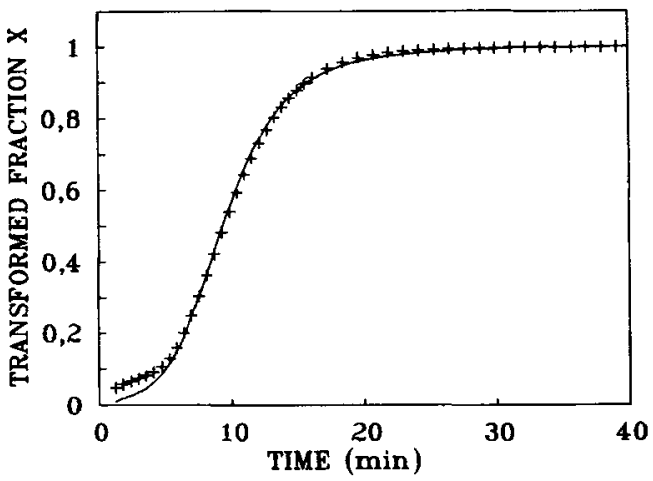

Fig.9: (a) Comparison of the measured transformation curve at $\mathrm{T}=130^{\circ} \mathrm{C}$ (represented by the symbols) with its description based on the AED and an individual standard Avrami fit /33/. (b) Comparison of the measured transformation curve at $\mathrm{T}=139^{\circ} \mathrm{C}$ (symbols) with a calculated transformation curve based on AED derived from the non-isothermal measurement with a heating rate of $\dot{\mathrm{T}}=$ $16 \mathrm{~K} / \mathrm{min}$ (solid line) $/ 33 /$.

The results described were presented using the example of $92 \%$ rolled material. If less deformed copper is studied, those results too are best described by a distribution of activation energies. Here the AED is displaced to higher energies with decreasing degree of deformation, increasing in width at the same time, Fig. $10 / 126 /$. In addition, there is an ever stronger inclination, with a tendency towards higher energies. The increase of the mean activation energy with decreasing degree of deformation can be explained by the reduced dislocation density. The distibution broadening can be understood as the consequence of a stronger presence of inhomogeneities in the dislocation structure of the less deformed material. As the inclination indicates, there is a tendency at low deformation to create more and more inhomogeneities which necessitate a particularly high activation energy, that is, areas which exhibit relatively poor recrystallization.

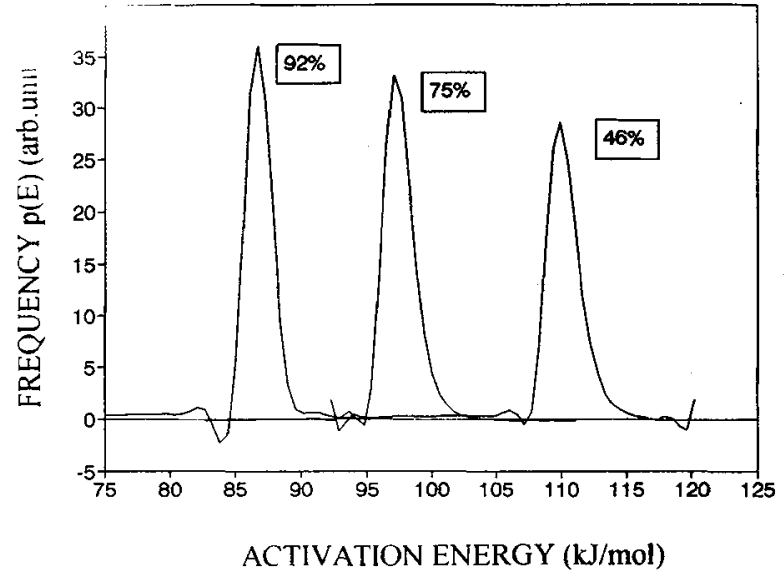

Fig.10: Activation energy distribution (AED) for different degrees of rolling /126/. 
Thus, the answer to the question raised about the use of calorimetric measurements can be summarized as follows:

(i) Based on the high accuracy of calorimetrically determined transformation data of recovery and recrystallization processes, extremely detailed and critical kinetic analyses may be performed.

(ii) The results of kinetic analyses allow conclusions to be drawn regarding

- the structure of the deformed state

- the mechanisms of the transformation process.

(iii) With the aid of a distribution of activation energies it is possible (at least in the present case) to predict the progress of the transformation for any isothermal and non-isothermal heat treatment.

Outlook: The foregoing presentation already indicates the future direction the development of calorimetric investigation of transformation kinetics will take. What is meant is the extension of calorimetric measurement by the specific combination with other methods of investigation, in order to increase the information yield with a view to the design of better models. In the first instance, it is a question of the combination with stronger locally measuring microstructural methods. Electron microscopy and the utilization of specially prepared model samples seems to be particularly promising. Computer modelling can help to classify and assess alternative explanatory concepts.

\section{References}

11/ Annealing Processes-Recovery, Recrystallization and Grain Growth, Proc. 7th Risø International Symposium on Metallurgy and Materials Science, Eds. N.Hansen, D.Juul Jensen, T.Leffers and B.Ralph, Risø National Laboratory, Denmark, 1986.

12/ Recrystallization '90, Proc.International Conference on Recrystallization in Metallic Materials, Wollongong 1990, Ed. T.Chandra, The Minerals, Metals and Materials Society, Warrendale, 1990.

13/ ICOTOM 9, Ninth International Conference on Textures of Materials, Avignon 1990, Textures and Microstructures 14-18 (1991).

14/ Grain Growth in Polycrystalline Materials, Proc. 1st. International Conference on Grain Growth in Polycrystalline Materials, Rome 1991, Eds. G.Abbruzzese and P.Brozzo, Materials Science Forum 94-96 (1992).

15/ Conference Set on "Fundamentals of Recrystallization", Zeltingen/Mosel 1992, Scripta Metallurgica et Materialia 27 (1992) 1445-1598.

16/ Proc. of the Symposium "Microscale Textures of Materials", Cincinnati 1991, Eds. B.L.Adams, H.Weiland and H.J.Bunge, Textures and Microstructures 20 (1993).

17/ Recrystallization '92, International Conference on Recrystallization and Related Phenomena, San Sebastian 1992, Eds. M.Fuentes and J.Gil Sevillano, Materials Science Forum 113-115, 1993.

18/ ICOTOM 10, Proc. of the 10th International Conference on Textures of Materials, Clausthal 1993, Ed. H.J.Bunge, Materials Science Forum 157-162 (1994).

19/ R.W.CAHN, in "High Temperature Aluminides and Intermetallics", Eds. S.H.Whang, C.T.Liu and J.O.Stiegler, The Minerals, Metals and Materials Society, Warrendale 1990, p.245.

/10/ N.HANSEN, D.J. JENSEN and Y.L.LIU, Ref. $/ 7 /$ p. 55.

/11/ E.HORNBOGEN, in "Phase Transformations '87", Proceedings of the Conference at the University of Cambridge. 1987, Ed. G.W.Lorimer, The Institute of Metals, London 1988, p. 394.

/12/ B.L.ADAMS, D.J.DINGLEY, K.KUNZE and S.I.WRIGHT, Ref. /8/ p. 31. 
/13/ W.F.HEMMINGER und G.W.H.HÖHNE, "Grundlagen der Kalorimetrie", Verlag Chemie, Weinheim/NewYork, 1979.

/14/ W.F.HEMMINGER und H.K.CAMMENGA, "Methoden der Thermischen Analyse", Springer Verlag, Berlin 1989.

/15/ J.GIL SEVILLANO, Ref. /7/ p. 19.

/16/ C.M.SELLARS, Ref. /7/ p. 29.

/17/ J.H.DRIVER, Ref. $/ 8 /$ p. 585.

/18/ N.HANSEN, Ref. $/ 5 /$ p. 1447.

/19/ M.HATHERLY, Ref. /5/ p. 1453.

/20/ P.HAASEN and P.J.WILBRANDT, Ref. $/ 8 /$ p. 887.

/21/ H.WEILAND and S.PANCHANADEESWARAN, Ref. $/ 6 /$ p. 67.

/22/ N.HANSEN and D.JUUL JENSEN, Ref. /8/ p. 1211.

/23/ K.SZTWIERTNIA and F.HAESSNER, Ref. /8/ p. 1291.

/24/ D.P.FIELD and H.WEILAND, Ref. /8/ p. 1181.

/25/ F.HAESSNER, in "Thermal Analysis in Metallurgy", Eds. R.D. Shull and A.Joshi, The Minerals, Metals and Materials Society, Warrendale 1992, p. 233.

126/ L.C.CHEN and F.SPAEPEN, J.Appl.Phys. 69 (1991) 679.

/27/ F.HAESSNER und J.SCHMIDT, Z.Metallkd. $\underline{85}$ (1994) 324.

/28/ L.RYDE, W.B.HUTCHINSON and S.JONSSON, Ref. /2/ p. 313.

129/ J.SCHMIDT and F.HAESSNER, Z.Phys.B.-Condensed Matter 81 (1990) 215.

/30/ E.WOLDT und F.HAESSNER, Z.Metallkd. 82 (1991) 329.

/31/ J.SCHMIDT and F.HAESSNER, Scripta metall mater. 25 (1991) 969.

/32/ F.HAESSNER and J.SCHMIDT, Acta metall.mater. 41 (1993) 1739.

/33/ P.KRÜGER and E.WOLDT, Acta metall.mater. 40 (1992) 2933.

134/ A.BERGER, P.J.WILBRANDT, F.ERNST, U.KLEMENT and P.HAASEN, Progress in Materials Science $\underline{32}$ (1988) 1.

/35/ F.J.HUMPHREYS and P.KALU, Ref. /3/ p. 703.

/36/ B.HUTCHINSON, Ref. /5/ p. 1471.

/37/ F.HAESSNER and K.SZTWIERTNIA, Ref. /5/ p. 1545.

/38/ F.HABIBY and F.J.HUMPHREYS, Ref. /6/ p. 125.

139/ A.AKEF and J.H.DRIVER, Ref. /7/ p. 103.

/40/ G.I.ROSEN, D.JUUL JENSEN and N.HANSEN, Ref. $/ 7 /$ p. 201.

/41/ O.ENGLER, E.ESCHER and N.HANSEN, Ref. /7/ p. 127.

/42/ B.J.DUGGAN, K.LÜCKE, G.KÖHLHOFF and C.S.LEE, Ref. /7/ p.121.

/43/ F.INOKO and K.KASHIHARA, Ref. /7/ p. 139.

144/ T.FURU, K.MARTHINSEN and E.NES, Ref. /7/ p. 41.

/45/ M.A.MORRIS, M.LEBOEUF and D.G.MORRIS, Ref. /7/ p. 257.

/46/ K.SZTWIERTNIA and F.HAESSNER, Ref. /8/ p. 1069.

/47/ D.G.MORRIS and M.A.MORRIS, Ref. /7/ p. 599. 
148/ U.WOLF, F.ERNST, T.MUSCHIK, M.W.FINNIS and H.F.FISCHMEISTER, Phil.Mag. A66 (1992) 991.

149/ V.RANDLE, "Grain Boundary Geometry in Cubic Polycrystals", Inst.Phys.Pub., Bristol 1993.

/50/ V.RANDLE, Ref. /8/ p. 175.

151/ E.IRABKIN, L.S.SHVINDLERMAN and B.B.STRAUMAL, Int.Journal of Modern Physics B, $\underline{5}$ (1991) 2989.

/52/ B.RALPH, Ref. /5/ p. 1509.

153/ D.WOLF and S.YIP (Eds), "Materials Interfaces: Atomic Level Structure and Properties", Chapman and Hall, London 1992.

154/ D.A.SMITH, Trans. Tech.Pub. (1992) 221.

/55/ G.GOTTSTEIN and L.S.SHVINDLERMAN, Ref. /5/ p. 1521.

/56/ R.WÜRSCHUM and R.W.BALLUFFI, phys.stat.sol. (a) 136 (1993) 323.

/57/ G.GOTTSTEIN and L.S.SHVINDLERMAN, Ref. /5/ p. 1515.

158/ T.GLADMAN, Ref. /4/ p.113.

/59/ B.RALPH, K.B.SHIM, Z.HUDA, J.FURLEY and M.EDIRISINGHE; Ref. /4/ p. 129.

160/ C.L.FUNKE, P.HAASEN, U.KLEMENT and P.J.WILBRANDT, Ref. /7/ p. 133.

/61/ V.RANDLE, Ref. /7/ p. 189.

/62/ G.PALUMBO and K.T.AUST, Ref. /2/ p. 101.

163/ H.V.ATKINSON, Acta Met. $\underline{36}$ (1988) 469.

164/ K.LÜCKE, G.ABBRUZZESE and I.HECKELMANN, Ref. /4/ p. 3.

165/ J.W.CAHN, E.A.HOLM and D.J.SROLOVITZ, Ref. /4/ p. 141.

/66/ H.J.BUNGE and E.DAHLEM-KLEIN, Ref. /7/ p. 299.

/67/ T.GLADMAN, Ref. /5/ p. 1569.

/68/ J.GASTALDI, C.JOURDAN and G.GRANGE, Ref. /4/ p. 17.

169/ U.CZUBAYKO, D.A.MOLODOV, B.C.PETERSEN, G.GOTTSTEIN and L.S.SHVINDLERMAN, Ref. /8/ p. 125.

/70/ F.J.HUMPHREYS, Ref. /2/ p. 113.

/71/ G.ABBRUZZESE and K.LÜCKE, Ref /1/ p. 1.

/72/ N.HANSEN, T.LEFFERS and J.K.KJEMS, Acta Met. 29 (1981) 1523.

173/ D.JUUL JENSEN, Neutron News $\underline{3}$ (1992) 20.

/74/ N.C.KRIEGER LASSEN, D.JUUL JENSEN and K.CONRADSEN, Ref. /8/ p. 149.

175/ S.I.WRIGHT and F.HEIDELBACH, Ref. /8/ p. 1313.

176/ Simulation and Theory of Evolving Microstructures, Proceedings of a Symposium sponsored by Computer Simulation Commitee of The Minerals, Metals and Materials Society, Indianapolis 1989, Eds. M.P.Anderson and A.D.Rollett, The Minerals, Metals and Materials Society, Warrendale, 1990.

/77/ R.T.DE HOFF, Ref. /1/ p. 35.

/78/ R.A.VANDERMEER and B.B.RATH, Ref. /2/ p. 49.

179/ R.D.DOHERTY, KANG LI, M.P.ANDERSON, A.D.ROLLETT and D.J.SROLOVITZ, Ref. /2/ p. 129. 
/80/ D.T.WALTON, H.J.FROST and C.V.THOMPSON, Ref. /4/ p. 531.

/81/ D.JUUL, JENSEN, Ref. /5/ p. 1551.

/82/ F.J.HUMPHREYS, Materials Science and Technology $\underline{8}$ (1992) 135.

/83/ H.HESSELBARTH, L.KAPS and F.HAESSNER, Ref. /7/ p. 317.

/84/ P.KRÜGER and E.WOLDT, Acta metall mater. 40 (1992) 2933.

/85/ C.M.SELLARS, Mater.Sci.Technol. 6 (1990) 1072.

/86/ J.J.JONAS, Ref. /2/ p. 27.

/87/ C.V.THOMPSON, Ref. /4/ p. 245.

/88/ F.F.LANGE, Ref. /7/ p. 81.

189/ E.NES and W.B.HUTCHINSON, in "Materials Architecture", Proc. of 10th Risø International Symposium on Metallurgy and Materials Science, N.Hansen et al Eds., Risø National Laboratory, Denmark, 1989.

/90/ E.FURUBAYASHI, Trans.Nat.Res.Inst.Metals 31 (1989) 1.

/91/ L.S.SHVINDLERMAN, Ref. /4/ p. 169

192/ Ref. /3/, Section IV, pp. 585.

193/ Ref. /8/, Section 3.2, pp. 887.

194/ J.HIRSCH. Ref. /1/ p. 349.

195/ R.PENELLE, T.BAUDIN, P.PAILLARD and L.MORA, Ref. /3/ p. 597.

196/ K.LÜCKE and O.ENGLER, Mat.Sci.Tech. 6 (1990) 1113.

/97/ E.FURUBAYASHI, M.NOBUKI and H.MIYAJ, Ref. /2/ p. 123.

198/ A.AKEF and J.H.DRIVER, Ref. /6/ p. 141.

199/ J.HARASE, Y.USHIGAMI and N.TAKAHASHI, Ref. /8/ p. 899

/100/ S.I.WRIGHT and F.HEIDELBACH, Ref. /8/ p. 1313

/101/ W.B.HUTCHINSON and E.NES, Ref. /1/ p. 107.

/102/ M.HATHERLY, Ref. /2/ p. 59.

/103/ O.ENGLER and K.LÜCKE, Ref. /5/ p. 1527.

/104/ H.J.BUNGE and U.KÖHLER, Ref. /5/ p. 1539

/105/ V.YU.NOVIKOV, Ref. /8/ p. 905.

/106/ J.HARASE, R.SHIMIZU, Y.YOSHITOMI, Y.USHIGAMI and N.TAKAHASHI, in "Modeling of Coarsening and Grain Growth", Eds. C.S.Pande and S.P.Marsh, The Minerals, Metals and Materials Society, Warrendale 1993, p. 245.

/107/ D.RAABE and K.LÜCKE, Ref. /8/ p. 597.

/108/ R.K.BOLINGBROKE and G.J.MARSHALL, Ref. /7/ p. 685.

/109/ W.B.HUTCHINSON, Ref. /8/ p. 1917.

/110/ Ref. /7/ Section 5.1., pp. 385.

/111/ H.J.MC QUEEN, E.EVANGELISTA and N.D.RYAN, Ref. /2/ p. 87.

/112/ S.R.CHEN and U.F.KOCKS, Ref. /5/ p. 1587.

/113/ J.J.JONAS and L.S.TOTH, Ref. /5/ p. 1575.

/114/ B.DERBY, Ref. /5/ p. 1581. 
/115/ M.J.LUTON and P.PECZAK, Ref. /7/ p.67.

/116/ J.J.JONAS, L.S.TOTH and T.URABE, Ref. /8/ p. 1713.

/117/ H.J. MC QUEEN, Ref. /7/ p. 429.

/118/ J.J.JONAS, Mat.Sc. and Eng. A 184 (1994) 155.

/119/ E.WOLDT and D.JUUL JENSEN, to be published in Met.Trans. A.

/120/ J.W.CHRISTIAN, The Theory of Transformations in Metals and Alloys, Part I, Chap. 12.

Pergamon Press, Oxford (1975).

/121/ E.WOLDT, J.Phys.Chem. Solids $\underline{53}$ (1992) 521.

/122/ R.D.DOHERTY, A.R.ROLLETT and D.J.SROLOVITZ, Ref. /1/ p. 53.

/123/ C.W.PRICE, Acta metall. 38 (1990) 727.

/124/ A.D.ROLLETT, D.J.SROLOVITZ, R.D.DOHERTY and M.P.ANDERSON, Acta metall. 37 (1989) 627.

/125/ A.D.ROLLETT, M.S.thesis, Drexel Univ. (1986).

/126/ E.WOLDT, unpublished results. 